Case Report

\title{
Deciphering Autoimmune Pancreatitis, a Great Mimicker: Case Report and Review of the Literature
}

\author{
Satya Allaparthi, Mohammed Sageer, and Mark J. Sterling \\ Lahey Clinic, Burlington, MA 01805, USA \\ Correspondence should be addressed to Satya Allaparthi; surgsatya@yahoo.com \\ Received 15 October 2014; Revised 21 December 2014; Accepted 23 December 2014 \\ Academic Editor: Haruhiko Sugimura
}

Copyright (C) 2015 Satya Allaparthi et al. This is an open access article distributed under the Creative Commons Attribution License, which permits unrestricted use, distribution, and reproduction in any medium, provided the original work is properly cited.

\begin{abstract}
Background. Autoimmune pancreatitis (AIP) is an atypical chronic inflammatory pancreatic disease that appears to involve autoimmune mechanisms. In recent years, AIP has presented as a new clinical entity with its protean pancreaticobiliary and systemic presentations. Its unique pathology and overlap of clinical and radiological features and absence of serological markers foster the disease's unique position. We report a case of diffuse type 1 autoimmune pancreatitis with obstructive jaundice managed with biliary sphincterotomy, stent placement, and corticosteroids. A 50-year-old Caucasian woman presented to our hospital with epigastric pain, nausea, vomiting, and jaundice. Workup showed elevated liver function tests (LFT) suggestive of obstructive jaundice, MRCP done showed diffusely enlarged abnormal appearing pancreas with loss of normal lobulated contours, and IgG4 antibody level was $765 \mathrm{mg} / \mathrm{dL}$. EUS revealed a diffusely hypoechoic and rounded pancreatic parenchyma with distal common bile duct (CBD) stricture and dilated proximal CBD and common hepatic duct (CHD). ERCP showed tight mid to distal CBD stricture that needed dilatation, sphincterotomy, and placement of stent that led to significant improvement in the symptoms and bilirubin level. Based on clinical, radiological, and immunological findings, a definitive diagnosis of AIP was made. Patient was started on prednisone $40 \mathrm{mg} /$ day and she clinically responded in 4 weeks.
\end{abstract}

\section{Introduction}

In 1961, Sarles et al. [1] first described a case series of unusual pancreatitis associated with obstructive jaundice and hyper-g globulinemia. However, it was not until 1995 that Yoshida et al. [2] termed autoimmune pancreatitis to describe a case of diffusely enlarged pancreas with irregularly narrowing pancreatic duct that was serologically associated with hyper-g-globulinemia, anti-nuclear antibody positivity, and responsivity to steroid treatment.

Clinically, AIP is characterized by protean symptoms that have many features in common with pancreatic cancer. These symptoms include abdominal pain, obstructive jaundice, weight loss, steatorrhea, new-onset diabetes mellitus (DM), and elevated levels of serum tumor markers. Hardacre et al. in their single institutional study reported that about $2.5 \%$ of pancreatoduodenectomies were performed in AIP patients following a mistaken diagnosis of pancreatic cancer [3]. Since AIP responds extremely well to steroid therapy, it is of utmost importance that it be differentiated from pancreatic cancer to avoid unnecessary laparotomy or pancreatic resection. AIP is frequently associated with other systemic autoimmune diseases, such as rheumatoid arthritis, Sjogren's syndrome, sarcoidosis, and inflammatory bowel diseases.

The diagnosis of AIP is challenging as it closely mimics pancreatic cancer. We further report a case of a 50-yearold Caucasian woman who presented with epigastric pain, nausea, vomiting, and jaundice. Subsequent workup revealed AIP as the etiology of her symptoms, and she was treated effectively with steroids.

\section{Case Presentation and Management}

A 50-year-old Caucasian woman presented to our hospital with 2-day duration of epigastric pain, nausea, vomiting, and jaundice. Her physical examination was unremarkable except for scleral icterus. An abdominal examination revealed epigastric tenderness without rebound. Laboratory investigations revealed hemoglobin $12.9 \mathrm{~g} / \mathrm{dL}$, white blood cell count $9.6 / \mu \mathrm{L}$, serum lipase $109 \mathrm{U} / \mathrm{L}$, serum amylase 

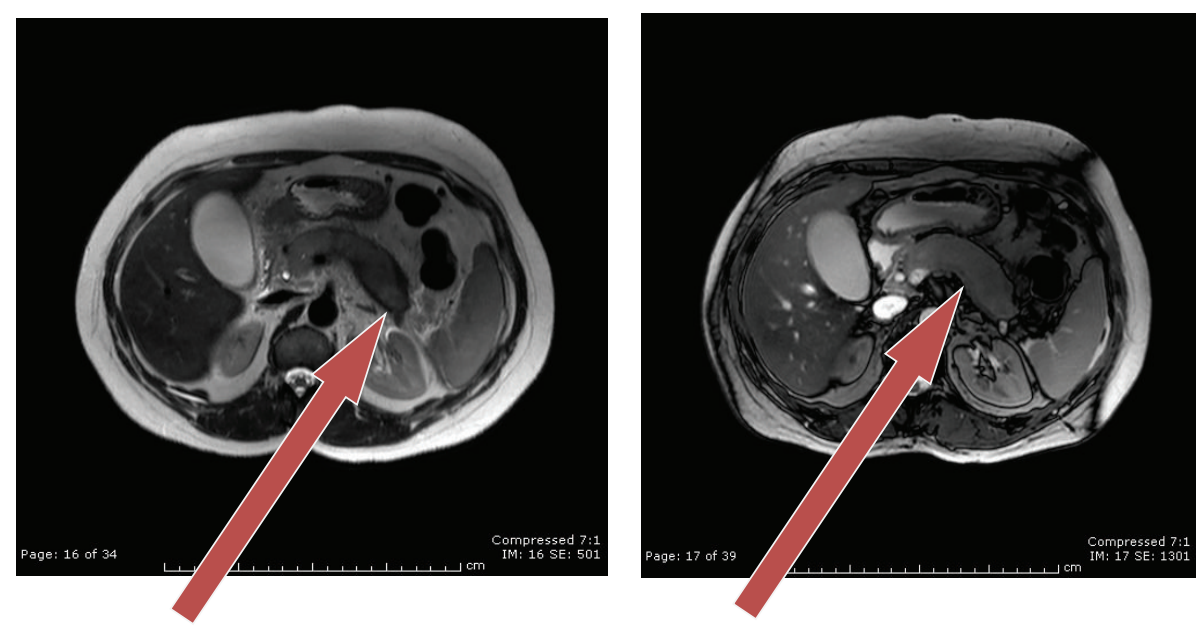

FIGURE 1: MRCP images arrow showing sausage-like pancreas in delayed phase.

$10 \mathrm{U} / \mathrm{L}$, and total bilirubin $10.6 \mathrm{mg} / \mathrm{dL}$ (direct and indirect fractions $8 \mathrm{mg} / \mathrm{dL}$ and $2.6 \mathrm{mg} / \mathrm{dL}$, resp.). Her liver enzymes were elevated (aspartate aminotransferase $110 \mathrm{U} / \mathrm{L}$, alanine aminotransferase $131 \mathrm{U} / \mathrm{L}$, and alkaline phosphatase $389 \mathrm{U} / \mathrm{L}$ ). Tests for hepatitis $\mathrm{A}, \mathrm{B}$, and $\mathrm{C}$ are negative and found to have elevated immunoglobulin IgG Ab level of $765 \mathrm{mg} / \mathrm{dl}$. Given these lab findings and clinical presentation, MRCP was further ordered which showed diffusely enlarged abnormal appearing pancreas with loss of normal lobulated contours. The pancreatic parenchyma is diffusely hypoenhancing, with focal hypoenhancement within pancreatic head, distal body, and tail (Figure 1). In view of her clinical presentation with worsening jaundice and MRCP findings, an endoscopic ultrasound (EUS) was done that revealed a diffusely hypoechoic and rounded pancreatic parenchyma with distal common bile duct (CBD) stricture and dilated proximal CBD and common hepatic duct (CHD) (Figure 2). Endoscopic retrograde cholangiopancreatography (ERCP) showed tight mid to distal CBD stricture that needed dilatation, sphincterotomy, and placement of stent that significantly improved her clinical symptoms and bilirubin level (Figure 3). She was started on tapering dose of prednisone $40 \mathrm{mg} /$ day and 4 weeks after treatment she improved clinically and radiologically. Our ability to recognize AIP and differentiate it from pancreatic adenocarcinoma is aided by the use of international consensus criteria.

\section{Discussion}

Autoimmune pancreatitis is rare disease with a much lower rate of incidence than its principal differential diagnosis, pancreatic cancer. The overall incidence and prevalence are still unclear owing to lack of prospective natural history studies. Study series from Japan have reported the prevalence of autoimmune pancreatitis in a range between 5 and $6 \%$ of all patients with chronic pancreatitis of which 6-8\% (0.82 per $100,000)$ had pancreatic resections performed for presumed pancreatic cancer $[4,5]$. Moreover, in the last two decades, there has been an increase in the number of reports of autoimmune pancreatitis in the medical literature; however, the overall number of patients is still relatively small. Though this clinical entity was well described initially in Japan, a growing awareness of the condition has led to reports around the world. Hamano et al. [6] reported that serum IgG4 levels are specifically elevated in Japanese patients with AIP; however, in further reported case series by Hirano et al. [7] and Pezzilli and Corinaldesi [8], an increase of IgG4 levels in AIP cohorts has been also confirmed in Western and Eastern countries. Although the pathogenesis of the disease is unknown, current evidence strongly suggests that an autoimmune process has been implicated $[9,10]$. Unlike most autoimmune conditions, AIP has a male predominance, with a male : female ratio of $2: 1$. The peak age of onset is the sixth and seventh decades $[5,9,11]$.

The histopathological hallmark findings in patients with AIP include dense infiltration of T lymphocytes, IgG4positive plasma cells, storiform fibrosis, and obliterative phlebitis in the pancreas; this form is termed lymphoplasmacytic sclerosing pancreatitis (LPSP) [12-14]. Of late, recent studies have provided evidence that there is another subtype of AIP with different histological findings named as idiopathic duct-centric pancreatitis (IDCP) that is more prevalent in Europe and the United States $[15,16]$. Recent studies showed consensus that LPSP and IDCP are regarded as two distinct subtypes of AIP, and it has been proposed that LPSP be called "type 1 AIP” and IDCP “type 2 AIP” $[17,18]$.

In 2011, an international panel of experts met during the 14th Congress of the International Association of Pancreatology held in Fukuoka, Japan, and an international consensus diagnostic criterion for AIP was proposed [19]. According to these, AIP is classified into type 1 and 2 . Five cardinal features of AIP are used: imaging of pancreatic parenchyma and ducts; serology; other organ involvement; pancreatic histology; and an optional criterion of response to steroid therapy. Each feature is categorized as a level 1 or 2 finding, depending on the diagnostic reliability (as shown in Table 1).

AIP should always be included in the differential diagnosis particularly in elderly presenting with obstructive 


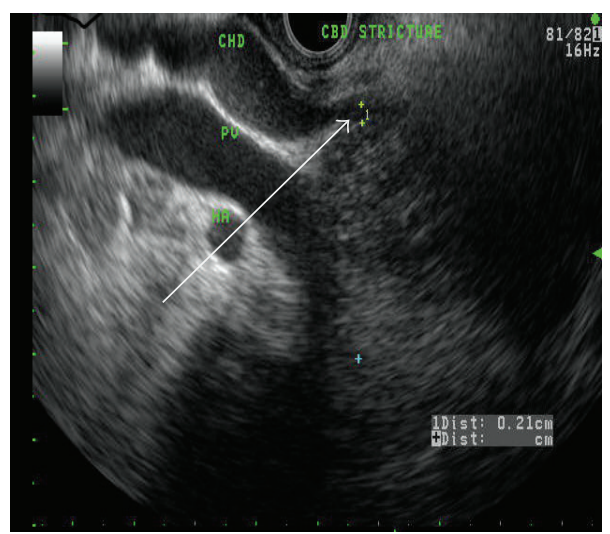

(a)

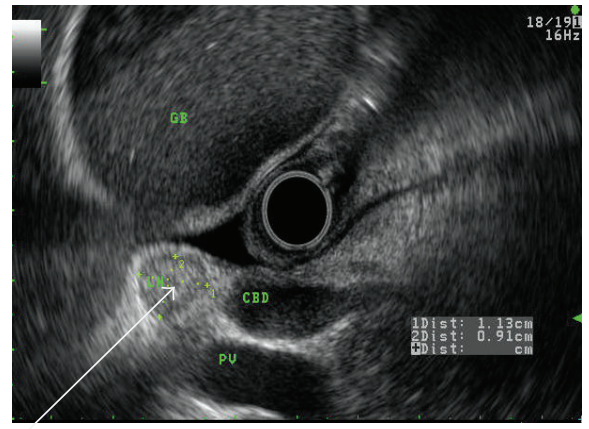

(c)

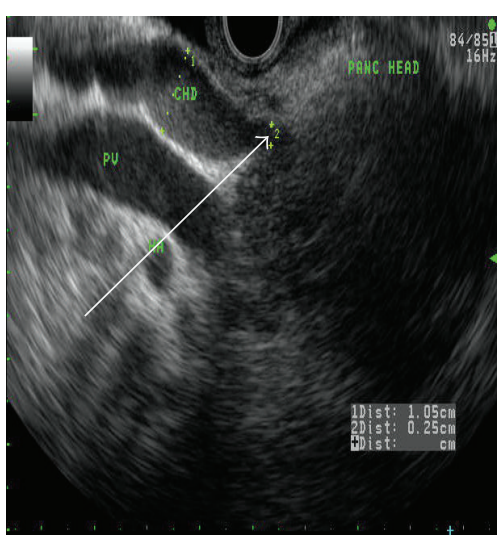

(b)

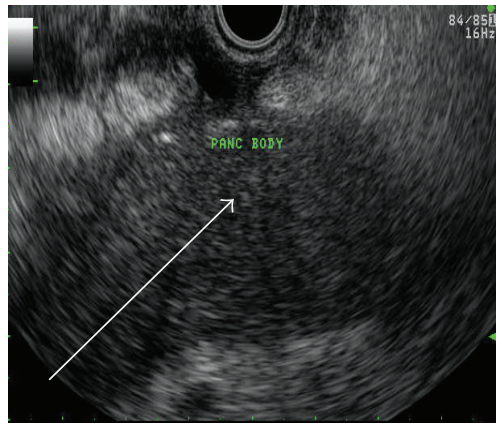

(d)

FIGURE 2: Endoscopic ultrasound images arrows showing (clockwise) (a) CBD stricture, (b) dilated CHD, (c) reactive lymph node, and (d) homogenous pancreatic body.

jaundice and a pancreatic mass. Prior to initiation of therapy, it is of paramount importance to differentiate AIP from pancreatic cancer. Various strategies help differentiate the clinical, immunological, and radiological presentations in between AIP and pancreatic cancer. Obstructive jaundice induced by bile duct stenosis secondary to pancreatic cancer typically progresses steadily, whereas the jaundice of AIP in IgG4-related sclerosing disease sometimes fluctuates or, in rare cases, improves spontaneously $[13,20]$. Elevated serum levels of IgG4 (>135 mg/dL) are seen in more than $90 \%$ of patients with AIP [6]. This is the most sensitive and specific diagnostic test for type I AIP, with 95\% sensitivity, $97 \%$ specificity, and $97 \%$ accuracy for discrimination from pancreatic cancer [6]. Ghazale et al [21] in their study series of pancreatic cancer patients 13/135 (10\%) noted that elevation of serum IgG4 levels alone cannot rule out pancreatic cancer, as only $1 \%$ of the above patients had elevated IgG4 levels $>280 \mathrm{mg} / \mathrm{dL}$, compared with $53 \%$ of AIP patients. Presence of other organ involvements such as bilateral salivary gland swelling, retroperitoneal fibrosis, and hilar or intrahepatic sclerosing cholangitis is highly suggestive of AIP rather than pancreatic cancer.

Radiological studies aid in differentiation based on the characteristic features on computed tomography (CT) and magnetic resonance imaging (MRI) that include diffuse or focal pancreatic enlargement, a peripancreatic capsule-like rim, enhancement at the late phase of contrast-enhanced images, and abnormal signal intensity on MRI. Diffuse enlargement of the pancreas and effacement of the lobular contour of the pancreas, the so-called "sausage-like" appearance, are a typical finding in AIP and are rarely seen in pancreatic cancer. On delayed phase of dynamic CT and MRI, enhancement of an enlarged pancreas is characteristic of AIP. As fibroinflammatory changes involve the peripancreatic adipose tissue, a capsule-like rim surrounding the pancreas is specifically detected in some AIP patients $[22,23]$. The role of transabdominal ultrasonography in the diagnosis of autoimmune pancreatitis is not well established. Ultrasonographic images of the pancreas, obtained transabdominally, are rarely diagnostic of autoimmune pancreatitis. Furthermore, findings on ultrasonography may be similar for autoimmune pancreatitis and for other forms of acute and chronic pancreatitis.

The hallmark finding on endoscopic retrograde cholangiopancreatography (ERCP) in patients with autoimmune pancreatitis is diffuse or segmental attenuation of the main pancreatic duct (MPD), in contrast to the segmental stenoses often encountered with pancreatic adenocarcinoma. The other common findings are narrowing of the intrapancreatic portion of the common bile duct, irregular narrowing of extrahepatic bile ducts, and, less frequently, enlarged intrahepatic bile ducts [24]. It is of paramount importance 


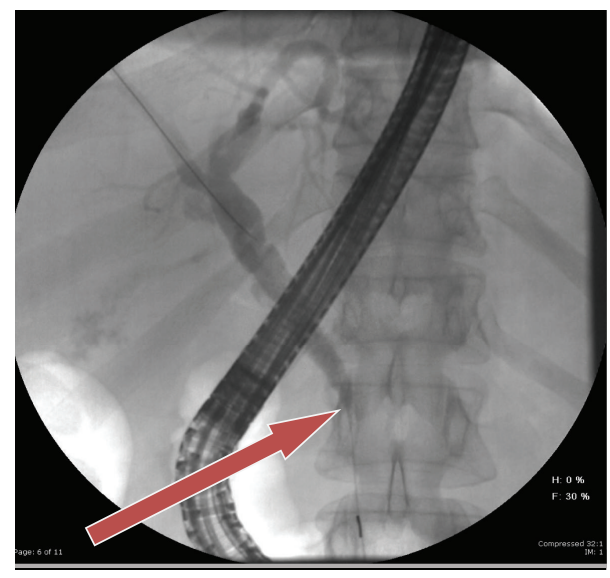

(a) Common bile duct stricture

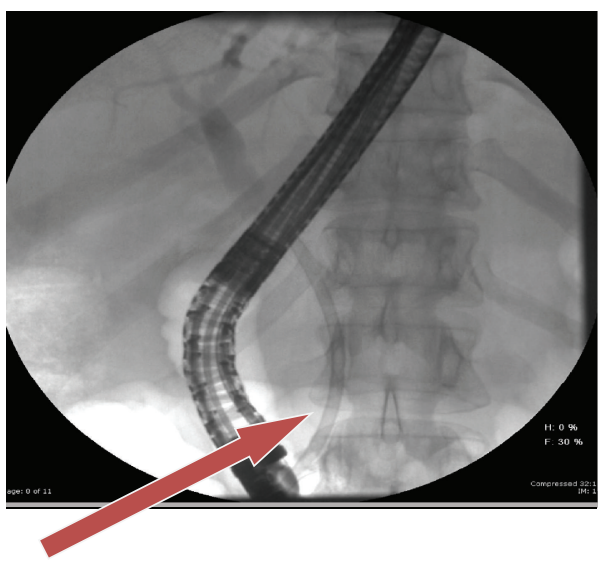

(c) Stent in common bile duct

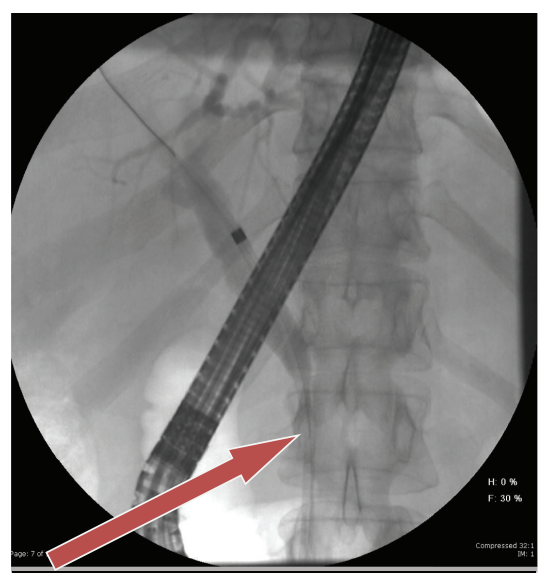

(b) Main pancreatic duct stricture

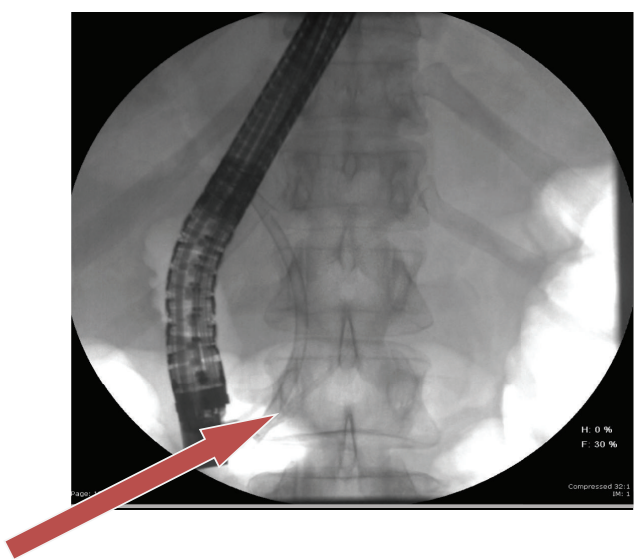

(d) Stent in main pancreatic duct

FIGURE 3: ERCP arrows showing CBD and MPD strictures pre stent insertion (a) and (b); post stent insertion (c) and (d) (clockwise).

to reliably distinguish AIP from PSC as making a reliable diagnosis is critical due to the often dramatic response of AIP related biliary strictures to steroid therapy in contrast to equivocal response seen in primary sclerosing cholangitis (PSC) and cholangiocarcinoma. The presence of a long, monomorphic stenosis of the intrapancreatic bile duct is suggestive of AIP, while band-like strictures, beading, or prune-tree appearance is most often found in PSC. Magnetic resonance cholangiopancreatography (MRCP) has become popular as a noninvasive method and it is becoming preferable to diagnostic ERCP. However, the narrowest MPD seen on ERCP cannot be visualized by MRCP due to the inferior resolution of MRCP compared with ERCP, so distinguishing between narrowing of the MPD in AIP and stenosis of the MPD in pancreatic cancer is not possible [25].

Endoscopic ultrasonography (EUS) emerged as a particularly important pancreatic imaging tool due to its ability to provide high-resolution imaging along with short working distances for transluminal pancreatic interventions. Though nonspecific, most common finding on EUS is diffuse or focal pancreatic enlargement inhomogeneous echo pattern, stranding and calcification [26]. EUS guided fineneedle aspiration or core biopsy of the pancreas may aid in the cytologic or histologic diagnosis; however, this approach to tissue acquisition was generally proven inadequate in providing a definitive diagnosis of AIP owing to a small sample size and lack of preserved tissue architecture and has not been evaluated in larger trials $[26,27]$.

\section{Conclusion}

In summary, we further report another case of AIP that reemphasizes the importance and various strategies of distinguishing it from pancreatic adenocarcinoma in order to avoid unnecessary surgical intervention. The concept of a "great mimicker" may be invoked and a heightened vigilance of AIP in one's differential diagnosis must be emphasized. As it is sometimes difficult to obtain adequate biopsy material from the pancreas, AIP is currently diagnosed based on careful consideration of a combination of characteristic clinical, serological, morphological, and histopathological features. More widespread use of pancreatic biopsy will aid in the diagnosis of autoimmune pancreatitis and provide a secure basis for the treatment with corticosteroids. Combined with a lack of prospectively validated clinical criteria that reliably establish the diagnosis, it is expected that the endoscopist 
TABLE 1: Level 1 and level 2 criteria for type 1 AIP.

\begin{tabular}{|c|c|c|}
\hline Criterion & Level 1 & Level 2 \\
\hline Parenchymal imaging & $\begin{array}{l}\text { Typical: diffuse enlargement with } \\
\text { delayed enhancement } \\
\text { (sometimes associated with } \\
\text { rim-like enhancement) }\end{array}$ & $\begin{array}{l}\text { Indeterminate (including } \\
\text { atypical): segmental/focal } \\
\text { enlargement with delayed } \\
\text { enhancement }\end{array}$ \\
\hline Ductal imaging (ERP) & $\begin{array}{l}\text { Long }(>1 / 3 \text { length of the main } \\
\text { pancreatic duct) or multiple } \\
\text { strictures without marked } \\
\text { upstream dilatation }\end{array}$ & $\begin{array}{l}\text { Segmental/focal narrowing } \\
\text { without marked upstream } \\
\text { dilatation (duct size, }<5 \mathrm{~mm} \text { ) }\end{array}$ \\
\hline Serology & $\begin{array}{l}\text { IgG4, >2x_upper limit of normal } \\
\text { value }\end{array}$ & $\begin{array}{l}\text { IgG4, 1-2x_upper limit of normal } \\
\text { value }\end{array}$ \\
\hline \multirow{11}{*}{ Other organ involvement (OOI) } & $a$ or $b$ & $a$ or $b$ \\
\hline & $\begin{array}{l}\text { (a) Histology of extrapancreatic } \\
\text { organs }\end{array}$ & $\begin{array}{l}\text { (a) Histology of extrapancreatic } \\
\text { organs including endoscopic } \\
\text { biopsy of bile duct }\end{array}$ \\
\hline & Any three of the following: & Both of the following: \\
\hline & $\begin{array}{l}\text { (1) Marked lymphoplasmacytic } \\
\text { infiltration with fibrosis and } \\
\text { without granulocytic infiltration }\end{array}$ & $\begin{array}{l}\text { (1) Marked lymphoplasmacytic } \\
\text { infiltration with fibrosis without } \\
\text { granulocytic infiltration }\end{array}$ \\
\hline & $\begin{array}{l}\text { (2) Storiform fibrosis } \\
\text { granulocytic infiltration }\end{array}$ & $\begin{array}{l}\text { (2) Abundant ( }>10 \text { cells/HPF) } \\
\text { IgG4-positive cells }\end{array}$ \\
\hline & (3) Obliterative phlebitis & \\
\hline & $\begin{array}{l}\text { (4) Abundant (>10 cells/HPF) } \\
\text { IgG4-positive cells }\end{array}$ & \\
\hline & (b) Typical radiological evidence & $\begin{array}{l}\text { (b) Physical or radiological } \\
\text { evidence }\end{array}$ \\
\hline & At least one of the following: & At least one of the following: \\
\hline & $\begin{array}{l}\text { (1) Segmental/multiple proximal } \\
\text { (hilar/intrahepatic) or proximal } \\
\text { and distal bile duct stricture }\end{array}$ & $\begin{array}{l}\text { (1) Symmetrically enlarged } \\
\text { salivary/lacrimal glands }\end{array}$ \\
\hline & (2) Retroperitoneal fibrosis & $\begin{array}{l}\text { (2) Radiological evidence of } \\
\text { renal involvement described in } \\
\text { association with AIP }\end{array}$ \\
\hline \multirow{6}{*}{ Histology of the pancreas } & LPSP (core biopsy/resection) & LPSP (core biopsy) \\
\hline & At least 3 of the following: & Any 2 of the following: \\
\hline & $\begin{array}{l}\text { (1) Periductal lymphoplasmacytic } \\
\text { infiltrate without granulocytic } \\
\text { infiltration }\end{array}$ & $\begin{array}{l}\text { (1) Periductal lymphoplasmacytic } \\
\text { infiltrate without granulocytic } \\
\text { infiltration }\end{array}$ \\
\hline & (2) Obliterative phlebitis & (2) Obliterative phlebitis \\
\hline & (3) Storiform fibrosis & (3) Storiform fibrosis \\
\hline & $\begin{array}{l}\text { (4) Abundant ( }>10 \text { cells/HPF) } \\
\text { IgG4-positive cells }\end{array}$ & $\begin{array}{l}\text { (4) Abundant ( }>10 \text { cells/HPF) } \\
\text { IgG4-positive cells }\end{array}$ \\
\hline
\end{tabular}

Reproduced with permission from 2012 Kamisawa, Tabata, Hara, Kuruma, Chiba, Kanno, Masamune, and Shimosegawa.

will continue to play a central role in the diagnosis and management of AIP in the future.

\section{Abbreviations}

AIP: Autoimmune pancreatitis

MPD: Main pancreatic duct

CBD: Common bile duct

CHD: Common hepatic duct
LPSP: Lymphoplasmacytic sclerosing pancreatitis

IDCP: Idiopathic duct-centric pancreatitis

CT: Computer tomography

MRI: Magnetic resonance imaging

MRCP: Magnetic resonance cholangiopancreatography

ERCP: Endoscopic retrograde cholangiopancreatography

EUS: Endoscopic ultrasound-guided fine needle aspiration. 


\section{Conflict of Interests}

The authors declare that there is no conflict of interests regarding the publication of this paper.

\section{Authors' Contribution}

Satya Allaparthi, Mohammed Sageer, and Mark J. Sterling reviewed, designed, edited, and organized the report; Mark J. Sterling served as the attending doctor for the patient and performed the ERCP; Satya Allaparthi performed the literature review and wrote the paper.

\section{References}

[1] H. Sarles, J.-C. Sarles, R. Muratore, and C. Guien, "Chronic inflammatory sclerosis of the pancreas-an autonomous pancreatic disease?" The American Journal of Digestive Diseases, vol. 6, no. 7, pp. 688-698, 1961.

[2] K. Yoshida, F. Toki, T. Takeuchi, S.-I. Watanabe, K. Shiratori, and N. Hayashi, "Chronic pancreatitis caused by an autoimmune abnormality. Proposal of the concept of autoimmune pancreatitis," Digestive Diseases and Sciences, vol. 40, no. 7, pp. 1561-1568, 1995.

[3] J. M. Hardacre, C. A. Iacobuzio-Donahue, T. A. Sohn et al., "Results of pancreaticoduodenectomy for lymphoplasmacytic sclerosing pancreatitis," Annals of Surgery, vol. 237, no. 6, pp. 853-858, 2003.

[4] K. P. Kim, M. H. Kim, M. H. Song, S. S. Lee, D. W. Seo, and S. K. Lee, "Autoimmune chronic pancreatitis," The American Journal of Gastroenterology, vol. 99, no. 8, pp. 1605-1616, 2004.

[5] I. Nishimori, A. Tamakoshi, and M. Otsuki, "Prevalence of autoimmune pancreatitis in Japan from a nationwide survey in 2002," Journal of Gastroenterology, vol. 42, no. 18, supplement, pp. 6-8, 2007.

[6] H. Hamano, S. Kawa, A. Horiuchi et al., "High serum IgG4 concentrations in patients with sclerosing pancreatitis," New England Journal of Medicine, vol. 344, no. 10, pp. 732-738, 2001.

[7] K. Hirano, Y. Komatsu, N. Yamamoto et al., "Pancreatic mass lesions associated with raised concentration of IgG4," American Journal of Gastroenterology, vol. 99, no. 10, pp. 2038-2040, 2004.

[8] R. Pezzilli and R. Corinaldesi, "IgG4 as a serological marker of autoimmune pancreatitis: the latest news," Journal of the Pancreas, vol. 5, no. 6, pp. 531-533, 2004.

[9] K. Okazaki, K. Uchida, M. Ohana et al., "Autoimmune-related pancreatitis is associated with autoantibodies and a Th1/Th2type cellular immune response," Gastroenterology, vol. 118, no. 3, pp. 573-581, 2000.

[10] T. S. Davidson, D. S. Longnecker, and W. F. Hickey, "An experimental model of autoimmune pancreatitis in the rat," American Journal of Pathology, vol. 166, no. 3, pp. 729-736, 2005.

[11] K. Notohara, L. J. Burgart, D. Yadav, S. Chari, and T. C. Smyrk, "Idiopathic chronic pancreatitis with periductal lymphoplasmacytic infiltration: clinicopathologic features of 35 cases," The American Journal of Surgical Pathology, vol. 27, no. 8, pp. 11191127, 2003.

[12] K. Okazaki, S. Kawa, T. Kamisawa et al., "Japanese clinical guidelines for autoimmune pancreatitis," Pancreas, vol. 38, no. 8, pp. 849-866, 2009.

[13] T. Kamisawa, K. Takuma, N. Egawa, K. Tsuruta, and T. Sasaki, "Autoimmune pancreatitis and IgG4-related sclerosing disease,"
Nature Reviews Gastroenterology and Hepatology, vol. 7, no. 7, pp. 401-409, 2010.

[14] K. Kawaguchi, M. Koike, K. Tsuruta, A. Okamoto, I. Tabata, and N. Fujita, "Lymphoplasmacytic sclerosing pancreatitis with cholangitis: a variant of primary sclerosing cholangitis extensively involving pancreas," Human Pathology, vol. 22, no. 4, pp. 387-395, 1991.

[15] D. H. Park, M.-H. Kim, and S. T. Chari, "Recent advances in autoimmune pancreatitis," Gut, vol. 58, no. 12, pp. 1680-1689, 2009.

[16] G. Zamboni, J. Lüttges, P. Capelli et al., "Histopathological features of diagnostic and clinical relevance in autoimmune pancreatitis: a study on 53 resection specimens and 9 biopsy specimens," Virchows Archiv, vol. 445, no. 6, pp. 552-563, 2004.

[17] T. Kamisawa, K. Notohara, and T. Shimosegawa, "Two clinicopathologic subtypes of autoimmune pancreatitis: LPSP and IDCP," Gastroenterology, vol. 139, no. 1, pp. 22-25, 2010.

[18] R. P. Sah, S. T. Chari, R. Pannala et al., "Differences in clinical profile and relapse rate of type 1 versus type 2 autoimmune pancreatitis," Gastroenterology, vol. 139, no. 1, pp. 140-148, 2010.

[19] T. Shimosegawa, S. T. Chari, L. Frulloni et al., "International consensus diagnostic criteria for autoimmune pancreatitis: guidelines of the international association of pancreatology," Pancreas, vol. 40, no. 3, pp. 352-358, 2011.

[20] T. Kamisawa, N. Egawa, and H. Nakajima, "Autoimmune pancreatitis is a systemic autoimmune disease," The American Journal of Gastroenterology, vol. 98, no. 12, pp. 2811-2812, 2003.

[21] A. Ghazale, S. T. Chari, T. C. Smyrk et al., "Value of serum IgG4 in the diagnosis of autoimmune pancreatitis and in distinguishing it from pancreatic cancer," The American Journal of Gastroenterology, vol. 102, no. 8, pp. 1646-1653, 2007.

[22] K. D. Bodily, N. Takahashi, J. G. Fletcher et al., "Autoimmune pancreatitis: pancreatic and extrapancreatic imaging findings," American Journal of Roentgenology, vol. 192, no. 2, pp. 431-437, 2009.

[23] T. Kamisawa, N. Egawa, H. Nakajima, K. Tsuruta, A. Okamoto, and N. Kamata, "Clinical difficulties in the differentiation of autoimmune pancreatitis and pancreatic carcinoma," The American Journal of Gastroenterology, vol. 98, no. 12, pp. 26942699, 2003.

[24] D. V. Sahani, S. P. Kalva, J. Farrell et al., "Autoimmune pancreatitis: imaging features," Radiology, vol. 233, no. 2, pp. 345-352, 2004.

[25] K. Takuma, T. Kamisawa, R. Gopalakrishna et al., "Strategy to differentiate autoimmune pancreatitis from pancreas cancer," World Journal of Gastroenterology, vol. 18, no. 10, pp. 1015-1020, 2012.

[26] J. J. Farrell, J. Garber, D. Sahani, and W. R. Brugge, "EUS findings in patients with autoimmune pancreatitis," Gastrointestinal Endoscopy, vol. 60, no. 6, pp. 927-936, 2004.

[27] M. J. Levy, R. P. Reddy, M. J. Wiersema et al., "EUS-guided trucut biopsy in establishing autoimmune pancreatitis as the cause of obstructive jaundice," Gastrointestinal Endoscopy, vol. 61, no. 3, pp. 467-472, 2005. 


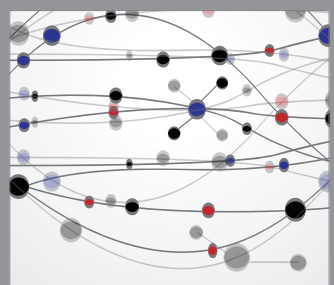

The Scientific World Journal
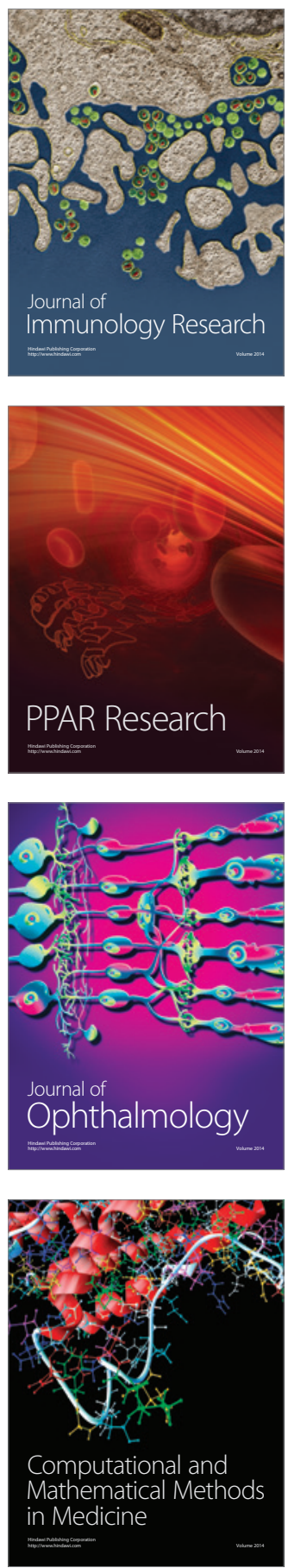

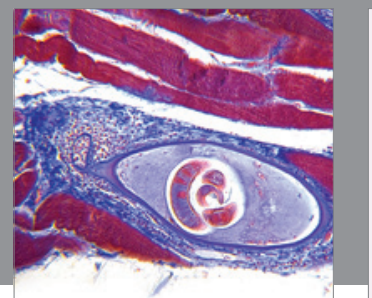

Gastroenterology

Research and Practice
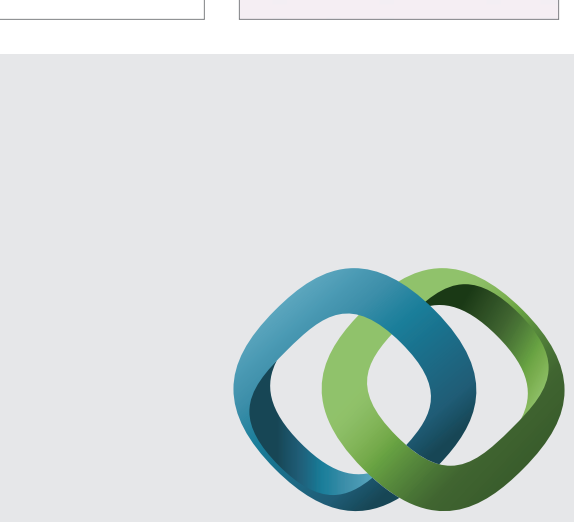

\section{Hindawi}

Submit your manuscripts at

http://www.hindawi.com
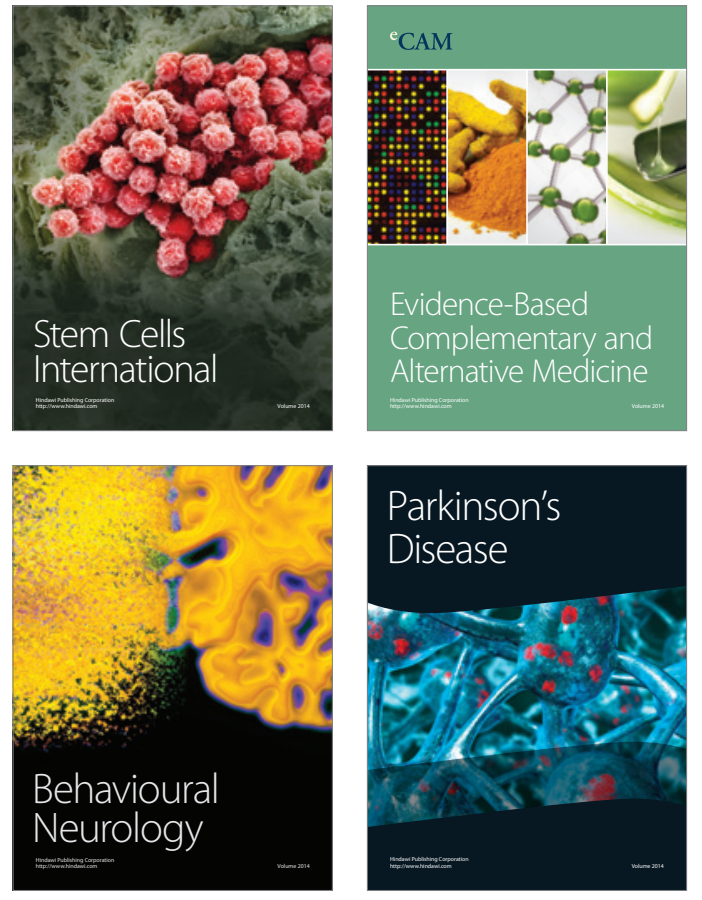
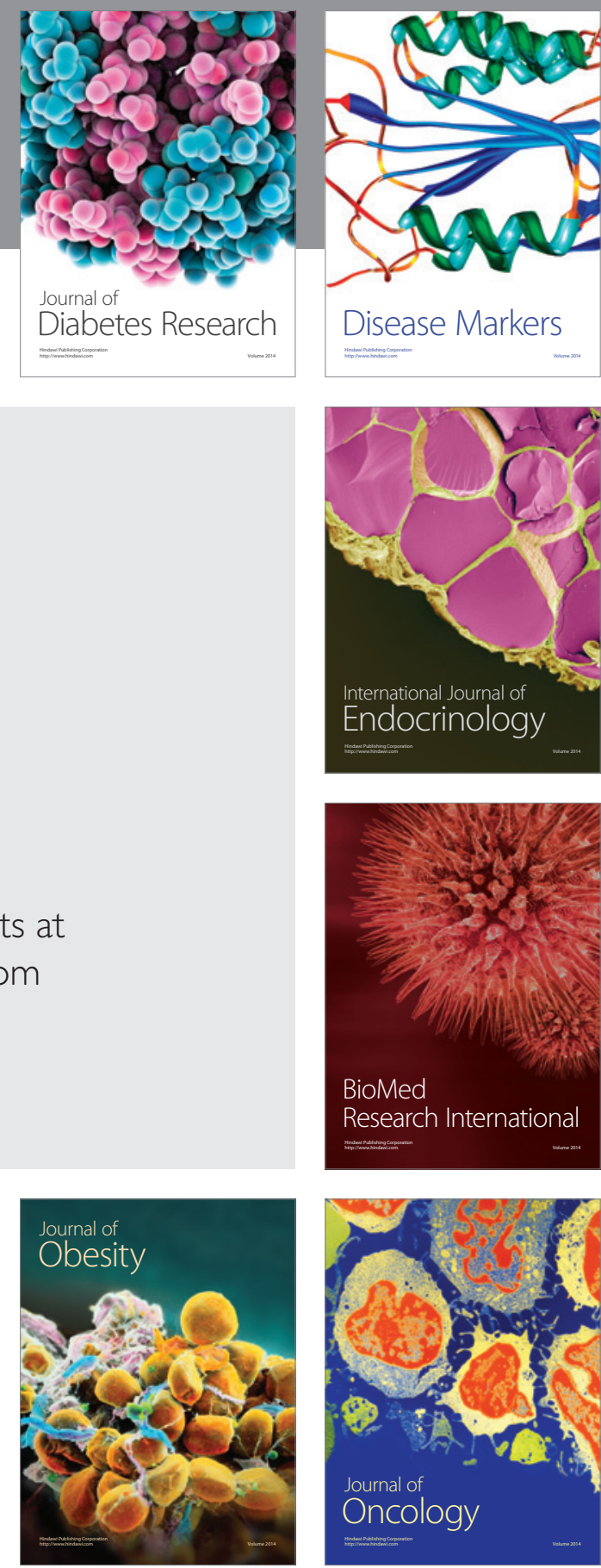

Disease Markers
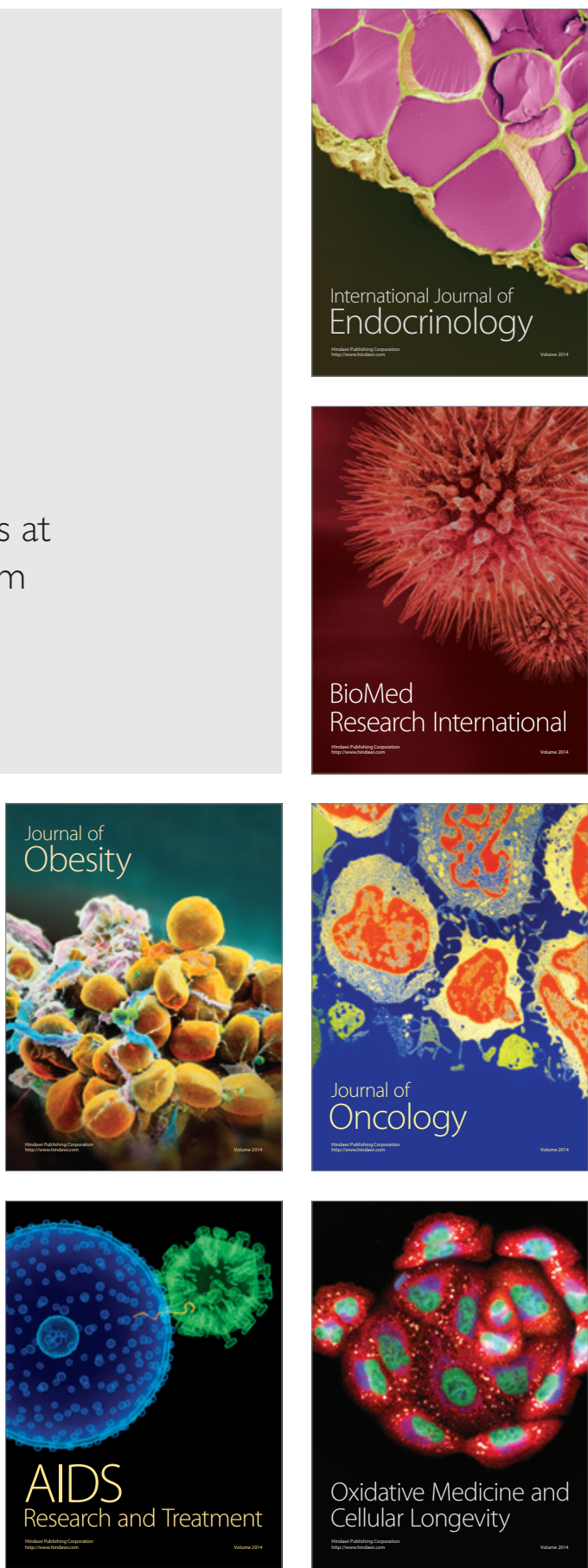